\title{
Edukasi Baby Yoga Untuk Stimulasi Pertumbuhan dan Perkembangan Bayi
}

\author{
Dewi Zolekhah ${ }^{1}$, Elvika Fit Ari Shanti ${ }^{2}$, Liberty Barokah ${ }^{3}$, Silvia Ari Agustina ${ }^{4}$ \\ 1,2,3,4, Universitas Jenderal Achmad Yani Yogyakarta, Indonesia \\ dewizolekhah87@gmail.com
}

\begin{abstract}
ABSTRAK
Pengabdian kepada masyarakat ini bertema "Edukasi Baby Yoga Untuk Meningkatkan Pertumbuhan dan Perkembangan Bayi. Pengabdian kepada masyarakat ini berfokus pada kesehatan bayi. Tujuan dari pengabdian kepada masyarakat ini diharapkan ibu yang mempunyai bayi mendapatkan pengetahuan tentang baby yoga yang mempunyai manfaat untuk meningkatkan pertumbuhan dan perkembangan bayi. Pengabdian ini berfokus pada kesehatan balita. Tujuan dari pengabdian kepada masyarakat ini adalah untuk meningkatkan pengetahuan ibu balita tentang tumbuh kembang bayi dan cara menstimulasi tumbuh kembang melalui baby yoga.

Pelaksanaan kegiatan ini direncanakan dalam tiga tahapan yaitu persiapan, pelaksanaan, dan tahap akhir. Tahapan persiapan meliputi serangkaian kegiatan dari pengkajian masalah dan penyusunan proposal. Tahapan pelaksanaan kegiatan adalah memberikan pendidikan kesehatan tentang baby yoga, demonstrasi dan melakukan baby yoga pada bayi di posyandu. Pada tahap pelaksanaan yang terakhir adalah melakukan evaluasi terhadap pengetahuan ibu setelah diberikan edukasi tentang baby yoga terhadap pertumbuhan dan perkembangan bayi. Tahap akhir yaitu berupa evaluasi hasil kegiatan dengan cara melihat dan mengamati ibu saat dilakukan edukasi baby yoga dan menganalisa pertumbuhan dan perkembangan bayi setelah dilakukan baby yoga.
\end{abstract}

Kata Kunci: Yoga, Pertumbuhan, Perkembangan

Received: November, 22, 2019

Revised: December 15, 2019

Accepted: February 20, 2020

\section{(i) (2)}

This is an open-acces article distributed under the terms of the Creative Commons Attribution-ShareAlike 4.0 International License.

\section{PENDAHULUAN}

Masa tumbuh kembang anak adalah masa yang sangat risiko bagi setiap kehidupan anak, maka sangat penting untuk memperhatikan semua aspek yang mendukung dan yang memengaruhi pertumbuhan dan perkembangan. Pertumbuhan dan perkembangan, dua peristiwa yang berbeda namun saling berkaitan dan saling memengaruhi. Keterlambatan tumbuh kembang anak salah satunya terlambatnya perkembangan motorik. Perkembangan motorik adalah proses tumbuh kembang kemampuan gerak seorang anak. Pada dasarnya, perkembangan ini berkembang sejalan dengan kematangan syaraf dan otot anak, sehingga setiap gerakan sesederhana apapun merupakan hasil pola interaksi yang kompleks dari 


\section{Journal of Community Engagement in Health}

http://jceh.org

ISSN: 2620-3758 (print); 2620-3766 (online)

https://doi.org/10.30994/jceh.v3i1.40

Vol.3 No.1. March 2020. Page.82-85

berbagai bagian dan sistem dalam tubuh yang dikontrol oleh otak. Pada umumnya keterlambatan pada setiap anak berbeda-beda tergantung proses pertumbuhan dan perkembangan masing-masing anak (Hardjadinata, 2009). Perkembangan motorik terganggu apabila kemampuan anak saat ini tidak sesuai dengan tahapan perkembangan motorik normal sesuai dengan usianya, misalnya pada usia 3 bulan anak belum bisa mengangkat kepala 45 derajat padahal anak usia 3 bulan harus sudah bisa mengangkat kepala 45 derajat. Beberapa teknik untuk membantu meningkatkan kemampuan aktifitas fungsional dengan optimal yaitu dengan terapi latihan meliputi exercise fleksor dan ekstensor knee, exercise tidur terlentang ke duduk, exercise kneeling dari crawling, exercise keseimbangan duduk pada guling, exercise keseimbangan pada bola, brain gym dan baby yoga (Hardjadinata, 2011).

Baby Yoga adalah olah tubuh yang melibatkan bayi secara menyeluruh (holistik) baik secara fisik maupun psikologis yang bermanfaat untuk pertumbuhan dan perkembangan bayi.. Secara fisik manfaatnya antara lain: meningkatkan fungsi dan kerja sistem pencernaan, sehingga bayi terhindar dari kembung, kolik atau sembelit, Membantu menyiapkan tubuh bayi agar mampu menguasai berbagai keterampilan. Mulai dari berguling, merangkak, duduk, hingga berdiri dan juga berlari. Baby yoga juga Membuat rileks tubuh bayi, sehingga bayi mudah tidur dan tidak rewel. Secara psikologis, dengan baby yoga, bayi akan mendapatkan rasa aman yang cukup karena latihan dilakukan bersama ibu, dan dapat memupuk rasa percaya diri anak secara dini dan lebih mendekatkan lagi hubungan emosi antara ibu dan bayi (Hardjadinata, 2011). Menurut beberapa penelitian, bonding memupuk rasa aman, percaya diri dan bahkan mencerdaskan anak. Karena secara otomatis, jika anak merasa aman dan nyaman dengan dengan dirinya maka proses belajar akan mulus, membantu pembentukan kepribadian bayi, tidak hanya sehat secara raga, tetapi juga secara psikologis dan mental (Ayah Bunda, 2015)

Baby yoga masih merupakan salah satu cara untuk menstimulasi pertumbuhan dan perkembanagn anak yang masih belum dikenal oleh masyarakat dibandingkan pijat bayi. Berdasarkan data dari bidan Koordinator dan kader di Posyandu Gamping, asuhan kebidanan komplementer seperti yoga bayi belum pernah dilaksanakan. Hal ini disebabkan karena masyarakat belum mengetahui baby yoga dan manfaatnya. Berdasarkan latar belakang diatas guna meningkatkan pengetahuan ibu mengenai baby yoga dan manfaanya maka untuk itu masih diperlukannya edukasi baby yoga terhadap pertumbuhan dan perkembangan bayi di Posyandu Tirtosari Patukan Utara, Ambarketawang Gamping, Sleman, Yogyakarta.

\section{METODE}

Pengabdian kepada masyarakat ini Di Posyandu Tirtosari Patukan Utara Ambarketawang Gamping, Sleman, Yogyakarta. Waktu pengabdian kepada masyarakat ini mulai dari bulan Oktober sd November 2019. Tahap persiapan meliputi studi pendahulan, perizinan, dan undangan dilakukan mulai bulan Oktober 2019. Pelaksanaan dilakukan 2 kali yaitu pada selasa, 19 November 2019 dan Jum'at, 21 November 2019 mulai pukul 15.00-17.00 WIB. Tahap Akhir yaitu Pelaporan di susun mulai tanggal 24-29 November 2019. Pengumpulan Laporan 2 Desember 2019. 


\section{HASIL DAN PEMBAHASAN}

Kegiatan pengabdian kepada masyarakat ini telah direalisasikan menjadi 3 tahap pelaksanaan. Tahap kegiatan 1 yaitu pada hari Selasa, 19 November 2019 Pukul 15.00- 17.00 WIB di Posyandu Tirtosari Patukan Utara, Ambarketawang Gamping, Sleman, Yogyakarta. Jumlah bayi yang datang yaitu sejumlah 30 bayi. Rangkaian kegiatan pada tahap 1 ini meliputi penyuluhan mengenai baby yoga serta manfaatnya untuk pertumbuhan dan perkembangan bayi. Tahap kegiatan yang kedua diadakan pada hari Jumat, 22 November 2019 pukul 15.0017.00 WIB yang dihadiri oleh 30 bayi. Kegiatan dalam tahap 2 ini yaitu demonstrasi dan praktik baby yoga. Selanjutnya dilakukan kegiatan tahap ketiga yaitu evaluasi.

Kegiatan berlangsung dengan lancar dengan susunan acara kegiatan sebagai berikut:

\section{Kegiatan 1: Penyuluhan}

Isi dari kegiatan ini adalah memberikan penyuluhan guna meningkatkan pengetahuan ibu mengenai materi baby yoga untuk meningkatkan pertumbuhan dan perkembangan bayi. Kegiatan ini di isi oleh 4 dosen yang dibantu oleh 4 mahasiswa.

\section{Tabel 5.4 Hasil Pre Test Penyuluhan Pengetahuan Ibu}

Berdasarkan data di atas dapat disimpulkan bahwa tingkat pengetahuan kader sebelum diberikan penyuluhan yaitu dengan kategori kurang ada 22 ibu $(73.33 \%)$ dan terdapat $8 \mathrm{ibu}(26.67 \%)$ dengan tingkat pengetahuan cukup.

\section{Kegiatan 2: Demontrasi dan Praktikum}

\begin{tabular}{|l|l|c|c|}
\hline No & Pengetahuan & Jumlah & $\%$ \\
\hline 1 & Baik & 0 & 0 \\
\hline 2 & Cukup & 8 & 26.67 \\
\hline 3 & Kurang & 22 & 73.33 \\
\hline \multicolumn{2}{|l|}{ Total } & 30 & 100 \\
\hline
\end{tabular}

Kegiatan yang kedua adalah demonstrasi oleh dosen yang dibantu oleh mahasiswa kemudian dilanjutkan masing-masing bayi dilakukan baby yoga dan ibu memperhatikan sembari terlihat sangat antusias dan senang anaknya dilakukan baby yoga. Kegiatan ini dilaksanakan pada hari Jum'at, 22 November 2019. Materi demonstrasi dan praktikum meliputi tahapan-tahapan baby yoga beserta manfaatnya untuk bayi. Ibu yang mempunyai bayi sangat antusias dalam mengikuti kegiatan baby yoga ini, hal ini terbukti $96 \%$ bayi dari keseluruhan bayi yang didata semua hadir.

\section{Kegiatan 3: Evaluasi}

Tahap terakhir dari kegiatan pengabdian ini adalah tahap evaluasi. Tahap evaluasi dalam penyuluhan dan demontrasi baby yoga ini dilakukan dalam 1 waktu. Untuk evaluasi pengetahuan tentang baby yoga dilakukan pada tanggal 22 November 2019 setelah semua bayi dilakukan baby yoga. Dari hasil evaluasi didapatkan hasil bahwa, ibu mempunyai pengetahuan yang baik tentang baby yoga dan ibu terlihat sangat antusias mengikuti demontrasi dan praktik baby yoga. 
Tabel 5.5 Hasil Post Test Penyuluhan Pengetahuan Kader

\begin{tabular}{|l|l|c|c|}
\hline No & Pengetahuan & Jumlah & Prosentase \\
\hline 1 & Baik & 18 & $60 \%$ \\
\hline 2 & Cukup & 12 & $40 \%$ \\
\hline 3 & Kurang & 0 & $0 \%$ \\
\hline \multicolumn{2}{|l|}{ Total } & 30 & 100 \\
\hline
\end{tabular}

Sumber : Data Primer, 2019

Berdasarkan data di atas dapat disimpulkan bahwa, tingkat pengetahuan ibu setelah diberikan penyuluhan yaitu dengan kategori baik ada $18 \mathrm{ibu}(60 \%)$ dan terdapat $12 \mathrm{ibu}$ (40\%) dengan tingkat pengetahuan cukup. Rencana tahap selanjutnya terkait dengan pengabdian kepada masyarakat ini yaitu mengenalkan dan mempraktekkan kids yoga untuk anakanak yang ada di posyandu Tirtosari Patukan Utara Ambarketawang Gamping Sleman.

Rencana lain untuk mengenalkan baby yoga sebagai salah satu stimulasi untuk pertumbuhan dan perkembanganan, akan dilaksanakan pengabdian yang serupa dibeberapa posyandu. Hal ini bertujuan agar baby yoga beserta manfaatnya dapat lebih diketahui dan diminati oleh masyarakat. Hasil dari baby yoga belum dapat terlihat hanya dengan satu kali melakukan baby yoga. Baby yoga harus dilakukan berkesinambungan setiap 2 minggu sekali minimal selama 1 bulan. Diharapkan bisa bekerja sama dengan pihak posyandu untuk dapat dilakukan baby yoga rutin setiap ada jadwal posyandu.

\section{KESIMPULAN}

Kegiatan pengabdian kepada masyarakat tentang edukasi baby yoga telah dilaksanakan sesuai dengan rencana yang disusun sebelum pengabdian dimulai. Kegiatan ini dinilai berhasil, mayoritas ibu mengalami peningkatan pengetahuan tentang baby yoga setelah penyuluhan dan memberikan manfaat positif setelah dilakukan baby yoga.

\section{REFERENSI}

Ayah bunda. (2015). Yoga untuk Bayi. https://www.ayahbunda.co.id/bayi-gizi-kesehatan/yogauntuk-bayi

Hardjadinata, YE.(2009). Keajaiban Kemampuan Sensori Bayi dan Cara Stimulasi. Dian Rakyat. Jakarta.

Hardjadinata YE. (2011). Yoga For Baby. Jakarta: Dian Rakyat

Aminah. 2009. Baby's Corner Kamus Bayi 0-12 bulan. Depok : Luxima Metro Media.

Gunardi, Winda dkk. 2008. Metode Pengembangan Perilaku dan Kemampuan Dasar Anak Usia Dini. Jakarta: Universitas Terbuka. 